\title{
A Contrastive Study of L1 and L2 Acquisition
}

\author{
Ahmad Moinzadeh \\ Faculty of Foreign Languages, Isfahan University, Isfahan 8174673441, Iran \\ Email: moin@ fgn.ui.ac.ir \\ Salman Dezhara \\ Faculty of Foreign Languages, Isfahan University, Isfahan 8174673441, Iran \\ Email: hamangt@hotmail.com \\ Omid Rezaei \\ Faculty of Foreign Languages, Isfahan University, Isfahan 8174673441, Iran \\ Email: omidrezaei.rezaei99@gmail.com
}

\begin{abstract}
This study aimed to give a comprehensive and all out analysis of the processes and aspects involved in first and second language acquisition and learning since this may cause a better selection of the teaching materials, methodologies, techniques and also a more efficient deployment and implementation of them in second or foreign language learning classes.
\end{abstract}

Index Terms - affective variables, behaviorism, psychomotor variables, cognitive variables, acquisition/learning, input

\section{INTRODUCTION}

Numerous studies have focused on finding the nature of the first and second language acquisition. The reason is clear, because they are wondering if a second language learner can learn the second language as effortlessly and perfectly as they did their first language. Why after having spent so many hours and effort in language learning classes, they find themselves unable to carry out a simple everyday conversation in 12 . The results of these studies also have valuable implications for language teachers which can help them to design their syllabuses, teaching processes and classroom activities. These results also enable the language teacher to understand his/her students' learning processes.

This study tries to review the issues in 11 and 12 contrastive studies and tackle the similarities and differences in the process of learning these two from different angles.

\section{CONSIDERATIONS IN COMPARING AND CONTRASTING L1 AND L2 LEARNing}

The contrast and comparison between L1 and L2 acquisition can be carried out in terms of psychomotor, cognitive, affective, linguistic and neurological variables. Psychomotor variable concern muscle control, and in regards to first and second language acquisition relate to the development of speech muscles that allow one to control complex sounds determining pronunciation and accent. Cognitive variable concern an individual's course of intellectual development, and hold several areas to compare first and second language acquisition. For example, an adult learning a second language could benefit from grammatical explanations and deductive thinking, whereas a child learning a first or second language would not. Affective variable concerns emotions. Linguistic variable concerns the differences and potential dissonance between the first and second language.

The point is that the above mentioned variables differ between children and adults, Brown (1994). So it is easier to compare young children learning an 11 and young children learning an 12. However the story is different in some countries like Iran where students start receiving their formal English language education in junior high school. As Brown (1994) believes the distinction should be made before and after puberty. This states the critical period hypothesis introduced by Lenneberg (1967) which holds that language acquisition should take pace during a critical period which ends at about the age puberty. It is then believed that any language learning which occurs after the age of puberty is slower and less successful than normal first language learning which of course not absolutely necessarily true. (Crashen, 1975; Lenneberg, 1967).

What follows is a brief discussion of each of the above mentioned variables which influence the process and nature of learning an 12 and accordingly the mechanism of the 11, 12 learning contrastive studies.

\section{A. Neurological Changes}

Research shows that as the brain develops, certain functions are assigned or so called lateralized to either hemisphere, it is believed that logical and analytical functions are located in the left hemisphere while the right hemisphere controls functions related to emotional and social needs. Language function appears to be controlled mainly in the left 
hemisphere. Lennenberg (1967) believes that this process happens gradually starting from the age of two and continue to the age of puberty. Now the point as Scovel (1969) puts it is that, while the brain functions, one of which is the language are assigned to the hemispheres and due to the plasticity of the brain prior to puberty, a child can learn a second language in addition to his/her mother tongue. This completion of the lateralization process as he says is the cause of the difficult the 12 earners may have after the age of puberty in having full command of the second language they are learning.

\section{B. Acquisition/Learning Hypothesis}

There is a distinction between learning, the explicit, conscious knowing about the language that occurs through instruction and classrooms practices and the acquisition of the language which is the way a child get the language, Krashen (1982). Though an adult can learn and acquire a second language if he is put in the write setting, however according to what Krashen says, learning cannot be turned to acquisition.

\section{Physical Changes}

A neurologically related issue is the psychomotor or the control over our articulatory muscles. This gives us the accent we have in our speech which include (throat, larynx, mouth, lips, tongue, and other muscles).

According to Brown (1994), the development of the child's speech muscles is a large contributing factor to the attainment of native-like pronunciation. This control over articulatory muscles is at first basic and then develops to handle more complex sounds which may last more than the age of 5 to be completed. Now the point is that due to the muscular plasticity of children they can acquire a better pronunciation of a second language than an adult earner.

\section{Cognitive Changes}

Piaget (1929), in Larsen freeman 1991), outlines the cognitive devilment of a child b his age:

- The sensorimotor stage from ages 0 to 2

- The preoperational stage from ages 2 to 7

- The operational stage from ages 7 to 16

The cognition develops faster up to age of 16 and then it gets slower. After the age of puberty and the maturation of the cognition, adults have the advantage of solving the problems by using their cognitive abilities and general information processing. Skehan (1988). And this is why they may benefit from deductive learning of language structures and grammar. Meaningfulness in such learning is possibly far more important for adults than for children, Ausubel (1964).

\section{E. Affective Changes}

The development of cognition in adult comes along with some affective obstacles on the way of learning a second language. One of them is inhibition. A child is highly egocentric, meaning his identity is highly flexible and pliable. As he grows up, he becomes more and more aware of himself and develops a more solid self-identity and after the age of puberty he tries to protect this identity. In case of language he develops a language ego with reference to the language he learns, Brown (1994).

The point here is that learning a new language for an adult means adopting a new ego along with an existing one related to the mother tongue. This feeling of clinging to the first ego causes an inhibition on the way of learning the second language.

Another affective factor casing difficulty for the learners is attitude. Since young children are not yet cognitively developed to raise a solid attitude toward a certain races, cultures, ethnic groups, and languages. The attitude that is established when the child grows up and if it is positive it can enhance the process of second language learning and vice versa, Ellis (1994). Stephen. Affective variables can act as a mental block, also termed affective filter, and prevent comprehensible input to be absorbed. When the learner is unmotivated and lacks confidence the affective filter goes up. When the learner is not anxious and wants to be a member of the group speaking the target language the filter goes down. He adds that children are at an advantage when learning a first or second language because their affective filter is low while adults are likely to have a higher affective filter due to events that occurred in adolescence McLaughlin (1987).

Along with the above mentioned, the social factor also influences the learning of the second language. A language is mostly acquired in a natural context and the social group in which the child is growing and yet in cases like the Iranian learners the context of learning of L2 differs from that of L1 since English is not spoken as a medium of communication outside of the confines of the classrooms and yet it is not taught along with the first language in the formal educational system. These social and educational differences play important roles in the learning process.

\section{F. The Behavioristic View}

These have been said, many studies that characterize the features of 12 acquisition are based on the issue of interlanguage. Selinker (1969, cited in McLaughlin, 1987) defines Inter-language as the interim grammars constructed by second language learners on their way to the target language. Inter-language is the learner's developing second language knowledge and has some characteristics of the learner's native language, of the second language, and some 
characteristics which seem to be very general and tend to occur in all or most Inter-languages. It is systematic, dynamic and constantly evolving. The phenomena that can be spotted in most language learners whose 12 learning have not simultaneously occurred with their 11 learning which is also the case of many Iranian English learners. However for a better and more informed analysis, let's take a look at some common arguments mentioned by Stern (1970) about teaching second language acquisition based on the processes of the first language acquisition.

- In language teaching we must practice and practice again and again. Just like a child learning his mother tongue, repeats things over and over again. During the language learning stage, he practices all the time. This is what we must do while learning a foreign language.

- Language learning is mainly a matter of imitation. You must be a mimic just like a child. He imitates everything.

- First we practice the separate sounds, then words, then sentences. This is the natural order and then is right for learning a foreign language.

- Watch a small child's speech development. First he listens and the he speaks. Understanding always precedes speaking. Then this must be the right order of presenting the foreign language.

- A small child listens and speaks and no one would dream of making him read or write. Reading and writing are the advanced stages of language development. The natural order for first and second language learning is listening, speaking, reading, and writing. You did not have to translate when you were small. If you were able to learn your own language without translation, you should be able to learn a foreign language in the same way

- A small child simply uses language. He does not learn a formal grammar. You don't tell him about verbs and nouns. Yet he learns language perfectly. It is equally unnecessary to use grammatical conceptualization in teaching a foreign language.

The statements above, represents the behavioristic view of language learning. All that have been discussed above were among the differences and similarities between a young child L1 learner and an adult L2 learner themselves. However there are aspects other than the learners that vary in the process of these two groups' language learning that will be tackled here.

\section{INPUT}

One of the big differences between a child learning an L1 in a natural setting and L2 learners in the classroom is the input they receive. Both in quality and quantity.

\section{A. Quantity of Input}

A child receives a torrent of L1 on a daily basis in a natural way while an L2 learner's exposure to the language he is learning is much more limited. In case of EFL setting like Iran it is even more marked. Students receive official English education when they start high school and are limited to one to three sessions 50 - 90 minute sessions per week and yet in most cases the English classes are held using L1. The importance of input has always been, marked by different theories and ideologies. The behaviorists believe that there is a one to one relationship between input and output which is learning. To get good results learners need to receive proper feedback which is the input. Stephen Krashen (1982) has put forward the Input Hypothesis which reveals the importance he places on input. He argues that the learner needs to receive comprehensible input to acquire language. The input a first language learner receives is simple and comprehensible at the beginning and gets slightly more complicated. Krashen believes that input should be slightly above the level of the language learner (i+1). Only in doing so can the second language learner move forward. He argues that the second language learner should be exposed to the target language as much as possible and that the lack of comprehensible input will cause the language learner to be held up in his development, Ellis (1994). Children are exposed to a day to day interaction and conversation that is tailored to the level of the understanding of the child. Most of this interaction is verbal at first so it is believed that this kid of constant verbal interaction is crucial for language learning since it helps to make the facts of the second language salient to the learner. The intersectional modifications that exist in the interaction of a native speaker with a non-native speaker make the input for the NNS comprehensible, Lightbown \& Spada, (2006)

\section{B. The Quality of Input}

As slightly mentioned above many scholars marked the importance of the comprehensible input which is the input a bit above the learner's level of competence is necessary to learn the second language though a problem with this i+1 is that it cannot be clearly defined. However Long (1983, cited in Ellis (1997) put emphasis on the interaction and the negotiation of meaning. By doing so the input is further modified adequately for the level of the learner. Another perspective on the role of interaction in language learning has been drawn from (Vygotsky's 1978, cited in Ellis, 1997) zone of proximal development theory. He maintains that children solve problems with the guidance of caretakers, who provide scaffolding; children then internalize these solutions.

Another point with the quality of the input received by the two groups of learners is the topics of the interaction. For a child the topics come from the immediate surrounding environment could then be further linked to things the child did before. This way the child can make associations between the input and the context of its use. Both the topic and the environment mostly are of the child interest. However in a classroom on the other hand, it is quite difficult for the 
teacher to always come up with something so interesting or so relevant that every student wants to find out more about it, Macnamara, (1975). He goes that it has been my experience that the topic is seldom generated by the students themselves. When the given topic is so far removed from their own cultural experiences, even those cognitively matured adult learners could face difficulty in comprehending the meaning at the onset.

Cook (1969) goes deeper in to the child's nature of interaction with others while learning his mother tongue and says, In an L1 learning situation, the child's response to modified speech triggers additional, even better adjusted input from the caretaker through intimate, supportive, personal interaction. The child supplies content words, and the caretaker empathetically constructs them into a sentence with the grammatical items missing in the child's utterance, and also expands the original sentence into a contextually meaningful form for the child. Different kinds of modifications are deployed in these interactions such as repetitions, clarification requests, comprehension checks, expansions, from others Larsen-Freeman and Long, (1991), however it is often impossible for the teacher to interact with each student on a person-to-person basis for a length of time even in a case of extended classroom interaction, the modifications are mostly limited to grammatical error corrections, cook (1969).

All in all it seems that as far as the above mentioned aspects of input are concerned the children have an advantage. However the question that weather or not they can transfer their L1 learning experiences to L2 learning is a matter of their age and the critical period hypothesis which was already discussed.

\section{IMPLICATIONS FOR THE TEACHERS}

In traditional classes in our country Iran teachers should raise the amount of input the students are receiving now. They should also try use English as the medium of communication inside the classrooms and incorporate the needed modifications to make the input comprehensible to the students. It is also implied from the L1 learning analysis that L2 learners should be encouraged to choose their own topics which they are interested in and the size of the classrooms should be smaller so that the teacher and students have the chance to spend more time having extended interactions around these topics.

Since in most Iranian English classrooms the focus is on conscious attention to language forms and the cognitive development of the students is used to learn the grammar and lexicon faster but the problem is that they will be forgotten easily and students cannot use what they have memorized through rote learning consciously, in practice. In this light, teachers should decrease on mechanical pattern drills and adopt a more communicative approach and activities that include increased and comprehensible input in L2.

As far as the learners are concerned they should be provided with an un threatening learning environment like that of a child as much as possible. They also should be given this view that English is a world language and should be presented with examples and well-known figures whose first language is not English to alleviate this extreme tendency toward the English speaking countries' cultures.

Another point is that since pronunciation is closely related to language ego Guiora, et al., (1972) it is better than learners start learning the L2 from earlier age for they are mentally and cognitively and emotionally more pliable and adaptable. Like a child learning his L1 in a fully contextualized setting, it is recommended to provide enough context and extra linguistic clues while teaching the language to learners in classes especially to younger learners of English.

\section{CONCLUSION}

Complex processes are involved in L1 and L2 learning and understanding and investigating these processes will help teachers to be more aware and involve the recommended language teaching tips though they shouldn't adhere to only a certain claim or factor. They should understand, analyze, synthesize and even criticize before trying to implement any of the suggestions made for teaching. They also should decide on a language theory so they adhere to it and combine it with their language teaching in classrooms.

\section{REFERENCES}

[1] Brown, H. D. (1994). Principles of Language Learning and Teaching ( $3^{\text {rd }}$ edn.) New Jersey: Prentice Hall.

[2] Ellis, R. (1994). The study of second language acquisition. China: Oxford University Press.

[3] Ellis, R. (1997). Second Language Acquisition. Oxford: Oxford University Press.

[4] Guiora, A., Brannon, R. and Dull, C. (1972). Empathy and Second Language Learning'. Language Learning, 22: 111-130.

[5] H. H. Stern (1970). Perspectives on second language teaching. The Ontario Institute for Studies in Education.

[6] Krashen, S.( 1975). The critical period for language acquisition and its possible bases. In D. Aaronson \& R. W. Rieber (Eds.), Developmental psycho- linguistics and communication disorders. New York: New York Academy of Sciences.

[7] Lenneberg, E. (1967). Biological foundations of language. New York: Wiley,.

[8] McLaughlin, B. (1991). Theories of second-language learning. Great Britain: Arnold.

[9] Krashen, S. (1982). Theory versus practice in language training. In R. W. Blair (Ed.), Innovative approaches language teaching. Rowley, MA: Newburry House Publishers.

[10] Larsen-Freeman, D. and Long, M.H. (1991). An Introduction to Second Language Acquisition Research. London: Longman

[11] Lightbown, P. M., \& N. Spada. (2006). How languages are learned (3rd ed.). China: Oxford University Press.

[12] Macnamara, J. (1975). Comparison Between First and Second Language Learning. Working Papers on Bilingualism, 7: 71-94. 
[13] McLaughlin, B. (1991). Theories of second-language learning. Great Britain: Arnold.

[14] Scovel, T. (1969). Foreign accents, language acquisition, and cerebral dominance. Language Learning, vol. 19, pp. 245-253

Ahmad Moinzadeh is currently assistant professor of linguistics at the department of English, faculty of foreign languages, university of Isfahan, Isfahan, Iran. He has instructed BA, MA and PhD courses at this department for many years. His main areas of research are syntax, comparative / contrastive linguistics, morphology and language acquisition he holds a PhD degree in linguistics, an MA degree in Linguistics and a BA degree on English language and literature.

Salman Dezhara, born in Iran, Mazandaran, Ramsar city in 1986/5/7. BA in ELT, Chaloos university, Chaloos, year 2009 . MA in ELT, Isfahan University, Isfahan, year 2011.

He worked as an English teacher in Shokooh English language institute for 2 years. And is a TOEFL test sessions supervisor in Isfahan university. He got acceptance for publication with the article titled: An Investigation of the Possible Effects of Favored Contexts in Second Language Vocabulary Acquisition in CCSE/ELT journal Canada, 2011.

Mr. Salman Dezhara has got his TTC license under the supervision of Kish English institute in year 2008 and passed the TOEFL test with the score 560 in 2008.

Omid Rezaei, born in Isfahan, Isfahan city, in 20/6/1988. BA in English Translation studies, Isfahan University in year 2010. MA in ELT, Isfahan University in year 2011.

He worked as an English teacher in reputed English language institutes in Isfahan and TOEFL \& IELTS tutor for 6 years and as TOEFL test sessions supervisor in Isfahan University. He got acceptance for publication with the article titled: An Investigation of the Possible Effects of Favored Contexts in Second Language Vocabulary Acquisition in CCSE/ELT journal Canada, 2011.

Mr. Omid Rezaei got his TTC license under the supervision of Pouyesh Inc in year 2007. He also passed the IELTS and scored 7.5 in year 2009. 